\title{
Novel Topology of a Multilevel Inverter Dedicated to Electric Traction Drive
}

\author{
Farid Kerrouche*, Farid Tazerart, Nabil Taib \\ Laboratoire de Technologie Industrielle et de l'Information (LTII), Université de Bejaia, Bejaia 06000, Algeria
}

Corresponding Author Email: farid.kerrouche@univ-bejaia.dz

https://doi.org/10.18280/ejee.220306

Received: 10 March 2020

Accepted: 6 May 2020

\section{Keywords:}

multilevel inverter, seven-level inverter, pulse width modulation, total harmonic distortion, PMSM, electric traction drive, field-oriented control

\section{INTRODUCTION}

The conventional two-level inverter is widely used. This is because of its advantages such as low cost, easy control and high-reliability, however, it presents some disadvantages among them the high switching frequency, high voltage change rate and electromagnetic interference and a very low level of operational safety, that would mean stopping the drive in the event one components failure. These deficiencies do not meet the design requirements of electric traction drive systems such as electric vehicles [1].

In order to overcome the disadvantages of conventional two-level inverter, multilevel topologies, as conventional Neutral Point Clamped NPC inverters and cascade $\mathrm{H}$ bridge CHB inverters, have been used as inverters for electric traction in some paper [1-3]. Multilevel inverters have demonstrated their superiority over two-level inverters in electric drives applications, but the use of a large number of power switches in these topologies is a major disadvantage which increases system cost and control complexity.

Multilevel inverters have become industrial solutions for applications requiring dynamic performance and high-power quality $[4,5]$. These inverters are potentially used in Electric drive applications such as train traction, boat propulsion and automotive applications [6].

The topologies indicated in the studies [7-12], being part of modular structure, contain polarity change cells, switching at the output voltage frequency. This topology needs a lot of isolated DC sources and some of them [7] requires several clamping diodes. This leads to making them more cumbersome and reduce their application areas where the size constraint is to be considerate. The topologies [13-15] involve several floating capacities. Topology [16] need three $\mathrm{H}$ bridges whereas two $\mathrm{H}$ bridges are sufficient in the conventional asymmetric cascade topology the proposed topology [17-19] their unique disadvantage is the high number of controllable switches.

All the above topologies, the major disadvantage is the high number of controllable switches in addition to already mentioned.

The previous research papers targeted optimization, either on the number of controllable switches or of the number of DC sources. Nevertheless, it will more interesting if a solution taken into account the both optimization parameters be proposed

This paper presents a new multilevel inverter topology with the lowest number of switches. The topology is based on single-phase seven-level inverters based in turn on a module which consists of two DC sources and three bidirectional switches.

This paper is organized in five sections. Section 2 is dedicated to the description and operating modes of the proposed topology, including its generalization either in number of levels or number of phases. Section 3 is divided into two parts. The first part is devoted to the control of the singlephase seven-level inverter of the proposed topology, the second part is for that of the derived three-phase structure. The application of the seven-level structure of the proposed topology in an electrical training based on the PMSM is presented in section 4 with the results and comments. The relevant conclusions are summarized in section 5 .

\section{PROPOSED TOPOLOGY}

The proposed topology, presented in Figure 1, is a combination of two three-level modules with DC sources of $\mathrm{Vdc}$ and $2 \mathrm{Vdc}$ respectively, allowing to get a seven-level inverter. The three-level modules consist of a bidirectional switch combined with a two-level inverter leg. The bidirectional switches of the two modules are noticed K2 and $\mathrm{K} 5$ where those of the legs are K1, K3, K4 and K6 respectively. 
The bidirectional switches are inserted to obtain all possible combinations of DC sources providing a high number of levels.

These DC sources, in case of electric vehicles, can be a batteries and/or capacitor in case of hybrid electric vehicles.

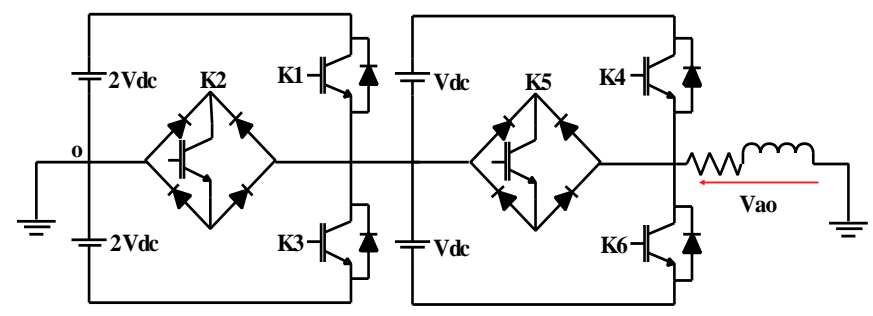

Figure 1. Seven-level inverter of the proposed topology

\subsection{Operation of seven-level inverter based on the proposed topology}

In order to well understand how the proposed topology operates, it is imperative to define the seven-level of the output voltage Vao. The different possible level could be generated, by the association of the two three-level modules shown in Figure 1, are seven: $3 \mathrm{Vdc}, 2 \mathrm{Vdc}, \mathrm{Vdc}, 0,-\mathrm{Vdc},-2 \mathrm{Vdc}$ and $3 \mathrm{Vdc}$, as illustrated in Figure 2. For this purpose, the control process, presented in Table 1 should be followed One can be seen that each level is synthesized by a combination of the six switches where two of them are ON and others are OFF.

All possible switching combinations are analyzed in this section, as shown in Figure 3. There can be only one switching combination for each output voltage level. The current flows of these seven different cases of the proposed inverter are shown in Figure 4, where the line in red means the conduction path.

Table 1. Switching table of switches for a phase of the proposed topology

\begin{tabular}{cccccccc}
\hline & K2 & K3 & K4 & K5 & K6 & Vao & IGBTs actives \\
\hline $\mathbf{1}$ & 0 & 0 & 1 & 0 & 0 & $3 \mathrm{Vdc}$ & 2 \\
$\mathbf{1}$ & 0 & 0 & 0 & 1 & 0 & $2 \mathrm{Vdc}$ & 2 \\
$\mathbf{0}$ & 1 & 0 & 1 & 0 & 0 & $\mathrm{Vdc}$ & 2 \\
$\mathbf{0}$ & 1 & 0 & 0 & 1 & 0 & 0 & 2 \\
$\mathbf{0}$ & 1 & 0 & 0 & 0 & 1 & $-\mathrm{Vdc}$ & 2 \\
$\mathbf{0}$ & 0 & 1 & 0 & 1 & 0 & $-2 \mathrm{Vdc}$ & 2 \\
$\mathbf{0}$ & 0 & 1 & 0 & 0 & 1 & $-3 \mathrm{Vdc}$ & 2 \\
\hline
\end{tabular}

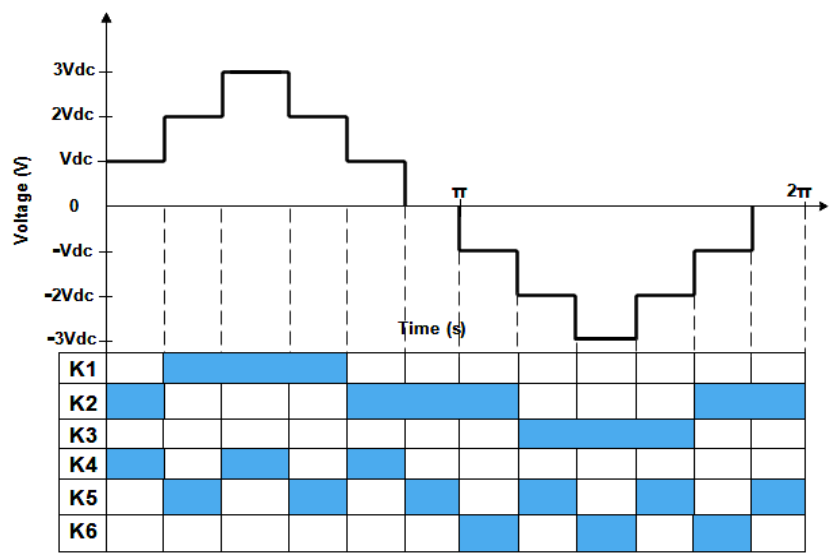

Figure 2. Switching states of the proposed seven-level inverter switches

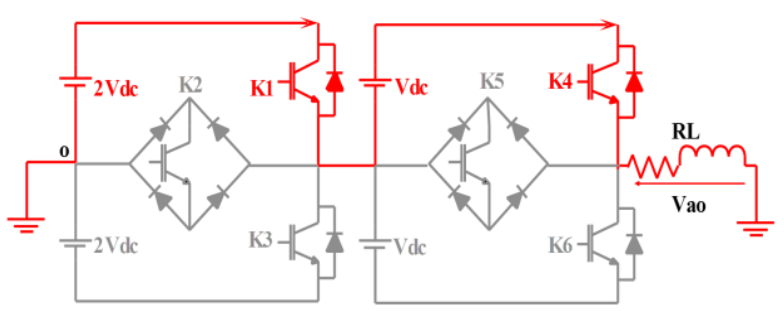

(a) $\mathrm{Vao}=3 \mathrm{Vdc}$

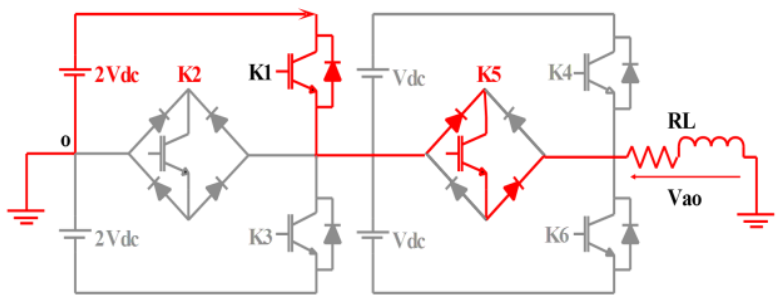

(b) $\mathrm{Vao}=2 \mathrm{Vdc}$

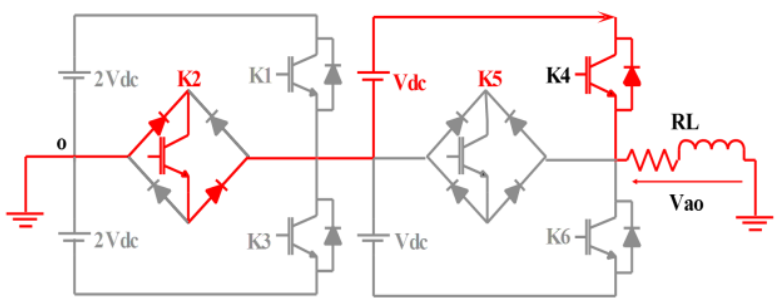

(c) $\mathrm{Vao}=\mathrm{Vdc}$

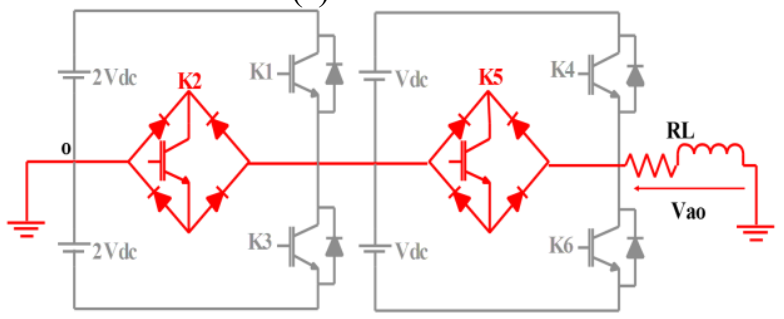

(d) $\mathrm{Vao}=0$

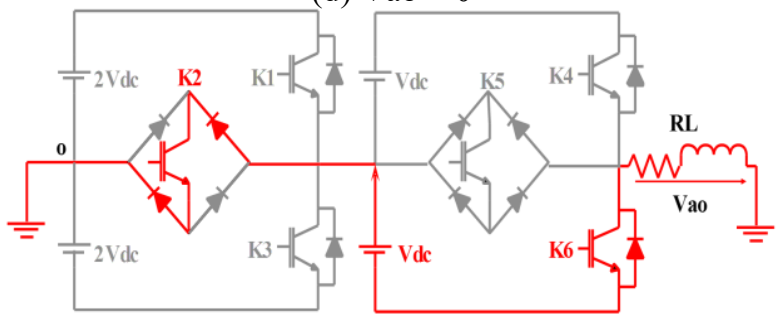

(e) $\mathrm{Vao}=-\mathrm{Vdc}$

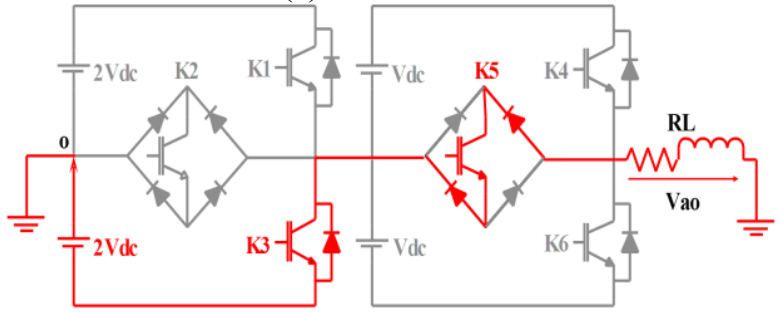

(f) $\mathrm{Vao}=-2 \mathrm{Vdc}$

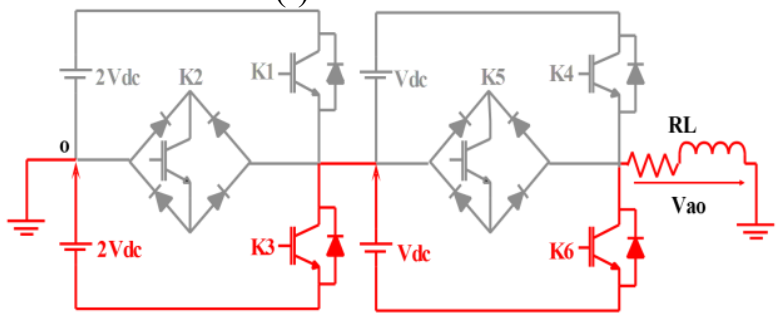

(g) $\mathrm{Vao}=-3 \mathrm{Vdc}$

Figure 3. Operating modes of single-phase seven-level inverter of the proposed topology 
(1) Positive output level $3 \mathrm{Vdc}$ (Figure 3 (a)): In the switching case of Figure 3 (a), the total voltage applied to the load is equal to $3 \mathrm{Vdc}$ when the two DC sources $2 \mathrm{Vdc}$ and $\mathrm{Vdc}$ are connected in series. For the $3 \mathrm{Vdc}$ voltage the switches $\mathrm{K} 1$ and $\mathrm{K} 4$ must be $\mathrm{ON}$ and $\mathrm{K} 2, \mathrm{~K} 3, \mathrm{~K} 5$ and $\mathrm{K} 6$ are OFF.

(2) Positive output level 2Vdc (Figure 3 (b)): In the switching state of Figure 3 (b), the total voltage applied to the load is equal to $2 \mathrm{Vdc}$. For this amplitude voltage the switches $\mathrm{K} 1$ and $\mathrm{K} 5$ are $\mathrm{ON}$ where and $\mathrm{K} 2, \mathrm{~K} 3, \mathrm{~K} 4$ and $\mathrm{K} 6$ are OFF.

(3) Positive output level 1 Vdc (Figure 3 (c)): In the case of configuration of Figure 3 (b), K2 and K4 are ON where K1, $\mathrm{K} 3$, K5 and $\mathrm{K} 6$ are OFF, the total voltage applied to the load is equal to $\mathrm{Vdc}$.

(4) Zero output level (Figure 3 (d)): To get zero voltage switches $\mathrm{K} 2$ and $\mathrm{K} 5$ must be $\mathrm{ON}$ and $\mathrm{K} 1, \mathrm{~K} 3, \mathrm{~K} 4$ and $\mathrm{K} 6$ are OFF.

(5) Negative output level $-1 \mathrm{Vdc}$ (Figure 3(e)): $-\mathrm{Vdc}$ is applied to the load in this switching case, switches K2 and K6 are $\mathrm{ON}$ where $\mathrm{K} 1, \mathrm{~K} 3, \mathrm{~K} 4$ and $\mathrm{K} 5$ are $\mathrm{OFF}$.

(6) Negative output level -2Vdc (Figure 3(f)): In the switching state of Figure 3 (b), the total voltage applied to the load is equal to $-2 \mathrm{Vdc}$. for this amplitude voltage the switches $\mathrm{K} 3$ and $\mathrm{K} 5$ are $\mathrm{ON}$ where $\mathrm{K} 1, \mathrm{~K} 2, \mathrm{~K} 4$ and $\mathrm{K} 6$ are $\mathrm{OFF}$.

(7) Minimum negative output level $-3 \mathrm{Vdc}$ (Figure $3(\mathrm{~g})$ ): In the switching case of Figure 3 (a), the total voltage applied to the load is equal to $3 \mathrm{Vdc}$ when the two DC sources $2 \mathrm{Vdc}$, $\mathrm{Vdc}$ are connected in series. For the $-3 \mathrm{Vdc}$ voltage $\mathrm{K} 3$ and $\mathrm{K} 6$ must be $\mathrm{ON}$ and $\mathrm{K} 1, \mathrm{~K} 2, \mathrm{~K} 4$ and $\mathrm{K} 5$ are $\mathrm{OFF}$.

\subsection{Extension of the proposed topology}

The proposed typology can be extensible in terms of the number of levels i.e. it is possible to increase the number of levels $\left(7,15,31 \ldots\left(2^{(\mathrm{M}+2)}-1\right)\right)$ by multiplying number of basic module units (Figure 4) with asymmetrical DC sources referring as illustrated in Figure 5, in this case the maximum phase voltage is given by Eq. (1):

$$
V_{\max }=\left(2^{(M+1)}-1\right) \cdot V_{d c}
$$

$\mathrm{M}$ is the number of modules to be added. The calculation of the number of levels $\mathrm{N}$ according to the number of modules to be added is given by Eq. (2):

$$
N=2^{(M+2)}-1
$$

The number of phases is also possible to increase taking into account the optimization of the DC sources number, Figure 5 illustrates the multiphase structure to this end, the structure of the proposed three-phase seven-level inverter designed from the base module (Figure 4) with an additional arm. Each arm is connected with a single base module shown in Figure 5.

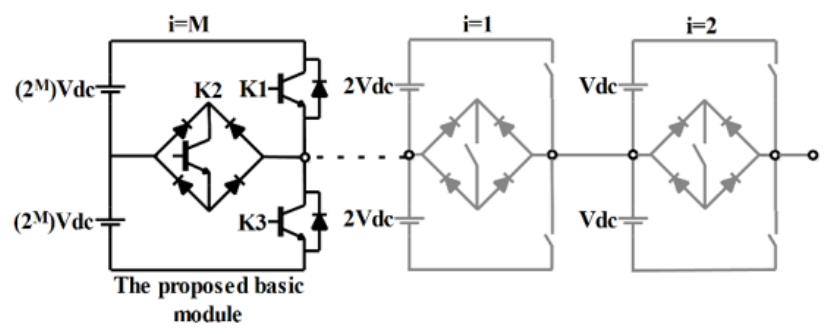

Figure 4. Extension of the proposed topology in terms of level

\subsection{Comparison}

Many research papers, over the last decade, have dealt with seven-level inverters. Hence, the proposed topologies are compared with the relevant ones and summarized in Table 2.

Table 2. Comparison between seven-level inverters

\begin{tabular}{cccc}
\hline Topologies & IGBTs & Diodes & Voltage sources \\
\hline Topology [7] & 8 & 12 & 4 \\
Topology [8, 11] & 10 & 10 & 3 \\
Topology [9] & 12 & 12 & 3 \\
Topology [10] & 8 & 10 & 3 \\
Topology [12] & 8 & 12 & 3 \\
Topology [13] & 12 & 12 & 5 \\
Topology [14, 18] & 10 & 10 & 4 \\
Topology [15] & 8 & 8 & 4 \\
Topology [16, 17] & 16 & 16 & 3 \\
Topology [19] & 9 & 9 & 3 \\
Proposed topology & $\mathbf{6}$ & $\mathbf{1 2}$ & $\mathbf{4}$ \\
\hline
\end{tabular}

The comparison is based on the number of power components used such as the number of diodes, number of bidirectional switches and a number of DC sources.

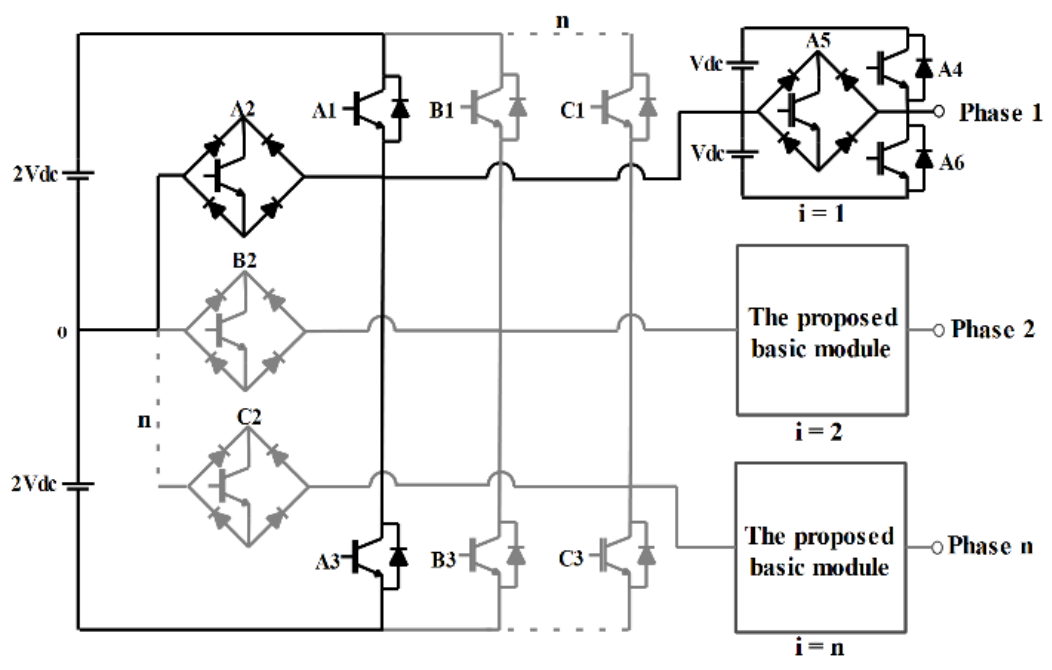

Figure 5. Extension of the proposed topology in terms of phase 
The proposed topology, compared to those already proposed, presents some advantages:

(1) The number of IGBT in the proposed topology is reduced compared to any topology of a seven-level, consequently reducing the cost and the complexity of the control with keeping the same waveforms quality in addition to the reduction of conducting and switching losses;

(2) The proposed topology can be generalized to $\mathrm{N}$ voltage levels and $\mathrm{N}$ voltage phases as described in section 2.2.

Moreover, the novel proposed topology of seven-level inverter keeps all advantages of the conventional multilevel inverter and eliminates their disadvantages. Compared with the NPC topologies, the proposed topology fixes the problem of neutral point balancing and the high number of capacitors. The CHB topologies have two drawbacks as the complexity of the control and the high number of isolated sources which are solved by the proposed one. Finally, the floating capacitor FC topologies contains several floating capacitors where the proposed topology is devoid of floating capacitors.

\section{SIMULATION AND RESULTS}

The proposed inverter topology and its control strategy may be tested by simulation in the following, the basic topology of the inverter can be useful is that of a single phase the results provided by seven-level single phase is presented that, in the aim of include the seven-level inverter in electrical traction drive, the three phase topology tested. Finally, performances of an electrical traction drive base of PMSM and the proposed three-phase seven-level inverter is shown.

\subsection{Single-phase topology}

In order to test the proposed multilevel topology, the single phase of the proposed seven-level topology feeding a load considered inductive. The control strategy of the inverter is simplified by choosing $T / 2$ as time duration of each level where is the output voltage period (Figure 2).

The simulation parameters are as follow:

$\mathrm{Vdc}=25 \mathrm{~V}$ and for the inductive load $\mathrm{R}=1 \Omega$ and $\mathrm{L}=10 \mathrm{mH}$.

Figure 6 shows the seven-level inverter with the different control signals of each IGBT over a period T and Figure 7 illustrates the voltage or terminal of the inductive load RL and the output current one can be seen that the seven voltage levels (3Vdc, 2Vdc, Vdc, 0, -Vdc, -2Vdc and -3Vdc).

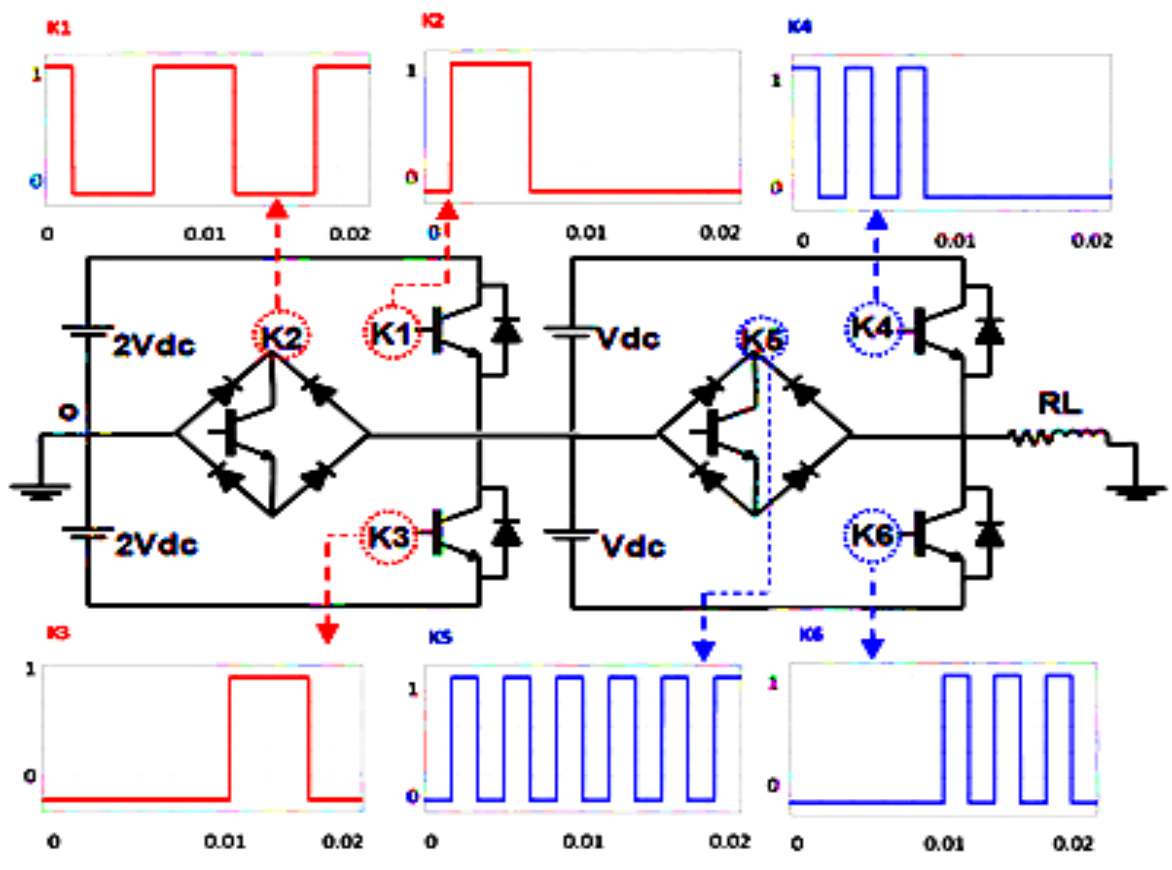

Figure 6. Switching patterns of the single-phase topology

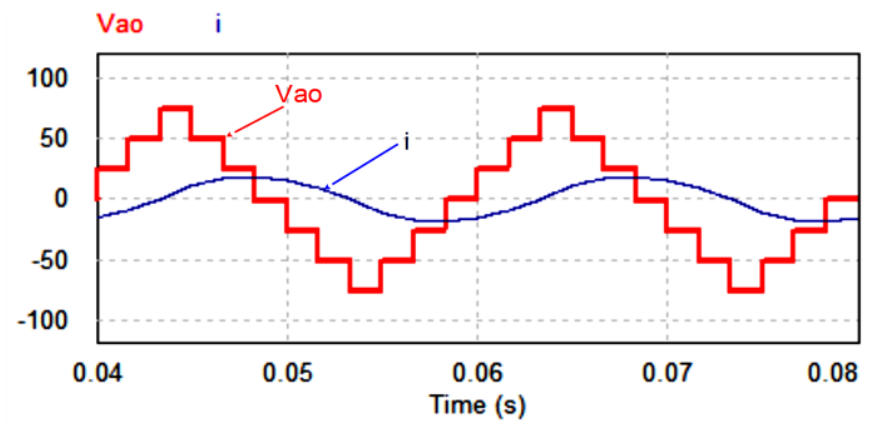

Figure 7. Output phase voltage Vao and current i 


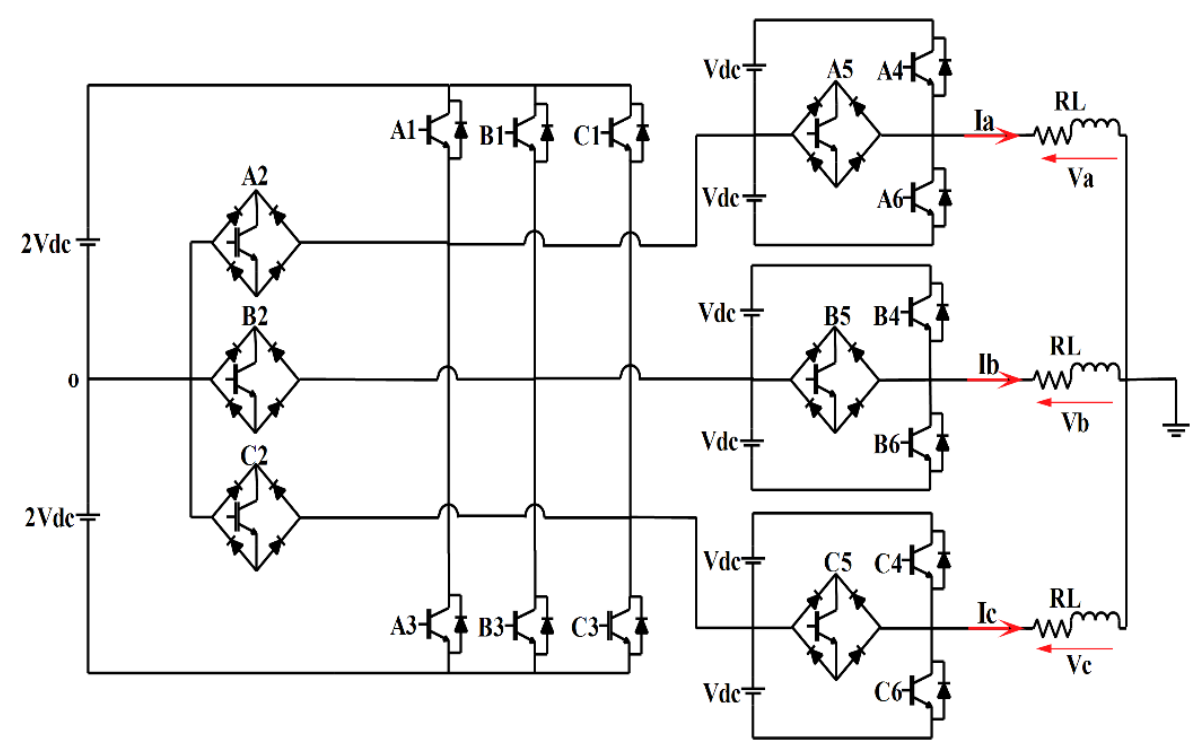

Figure 8. Proposed three-phase seven-level inverter
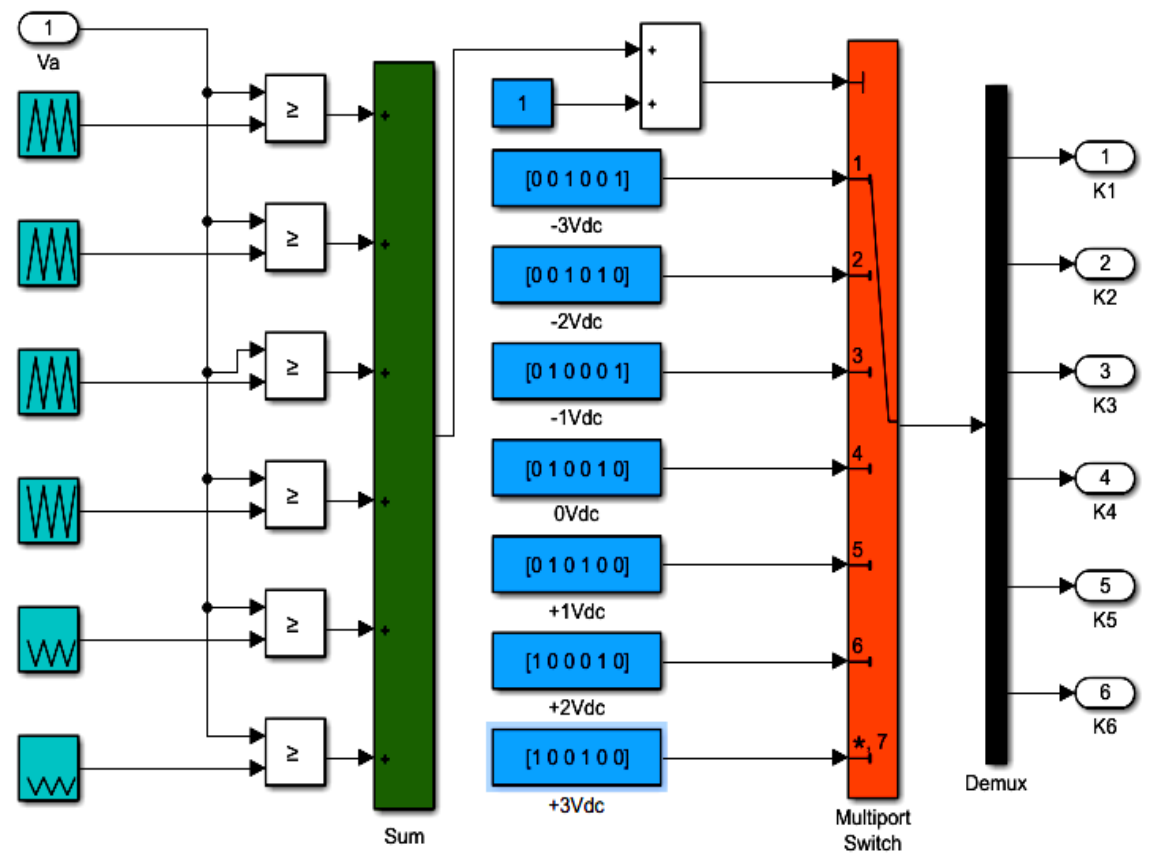

Figure 9. PWM Control technique of proposed topology

\subsection{Three phases seven-level inverter derived from the proposed topology}

In order to show the compliance with the conditions for reducing the number of controllable power components as well as the number DC source in case of multiphase, the description of the three- phase structure is given this latter is adopted since the three-phase systems are widely used.

The structure of the proposed three-phase seven-level inverter with is presented in Figure 8. The multi-carrier PWM is the more suitable for the multilevel inverters. This is because it is chosen to control the proposed seven-level topology as depicted in Figure 9. The principle of this control is the comparison of several overlapped high frequency triangular signals and a reference sine wave of the desired output voltages. In this work, the specifically control technique used is that phase opposition disposition pulse width modulation method (PODPWM) i.e. all operators have the same frequency and amplitude, all carriers below zero are antagonistic to those above zero [20].

The carrier signals which are $\mathrm{Cr} 1, \mathrm{Cr} 2, \mathrm{Cr} 3, \mathrm{Cr} 4, \mathrm{Cr} 5$ and Cr6 with reference wave arrangements are as shown in Figure 10.

To verify the performance of the proposed seven-level three-phase inverter, simulation work was performed in the MATLAB/Simulink environment. The simulation parameters are: $\mathrm{Vdc}=400 / 6 \mathrm{~V}$, switching frequency of $5 \mathrm{kHz}$ and $\mathrm{R}=1 \Omega$ and $\mathrm{L}=10 \mathrm{mH}$ for the inductive load.

Figures 11, 12 and 13 show the different output results of the load voltages, phase voltages, and current waveforms. Figure 12 clearly shows that the output voltage of proposed topology is a seven-level waveform. This has a direct impact on the currents waveforms which will be more interesting to show the enhancement of the performances of an electric traction drive system where it will be used. 


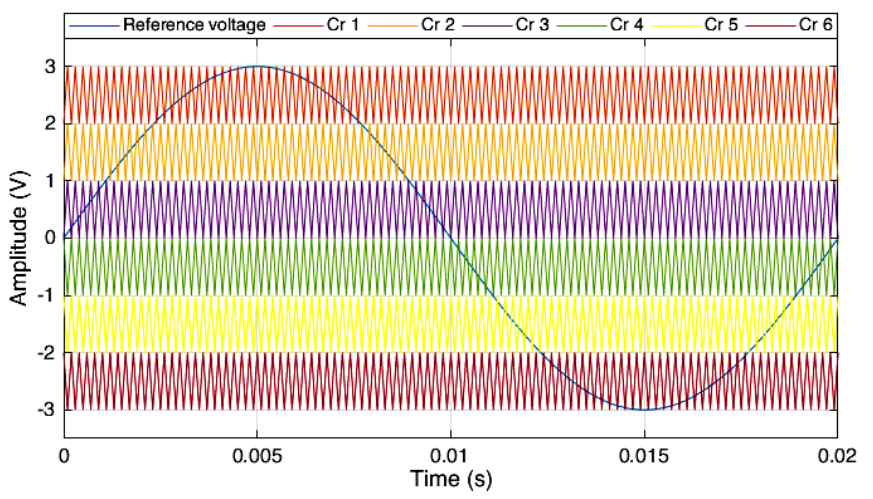

Figure 10. Multi-carrier PWM

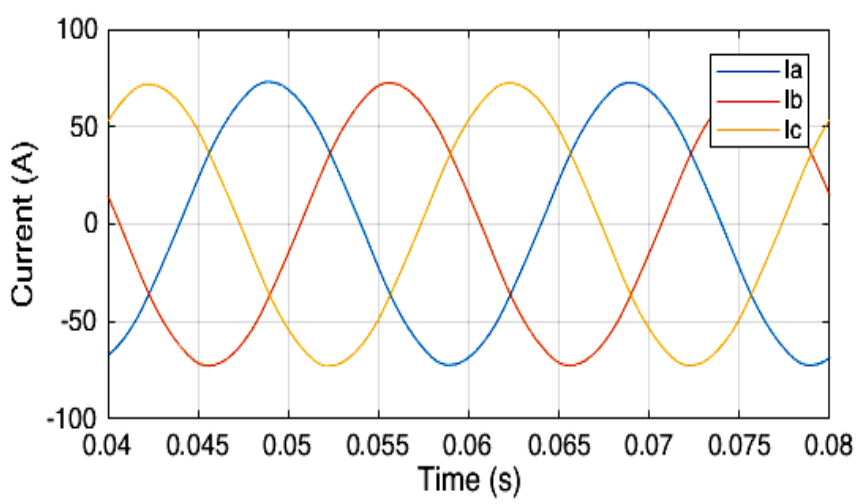

Figure 12. Output phase currents Iabc

\section{APPLICATION FOR ELECTRIC TRACTION DRIVE BASED ON PMSM}

The usefulness of the proposed topology can be shown by inserting it into an application. One of the promising applications is that of electric traction, case of electric vehicle

PMSMs are the most widely used in the field of motion control applications. This main is because reasons of their high-power density and high efficiency [21, 22].

The proposed seven-level inverter is used to feed the PMSM controlled by FOC technique as illustrated in Figure 14. Performances of the present global system have been verified by simulation with MATLAB Simulink.

Simulation results are shown in Figure 15-19 for $10 \mathrm{kHz}$ switching frequency and PMSM parameters summarized in Table 3.

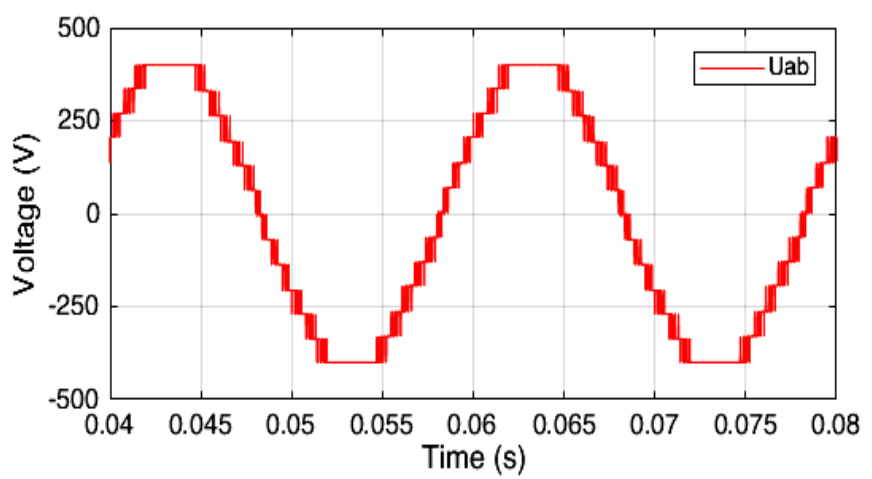

Figure 11. Output line voltage Uab

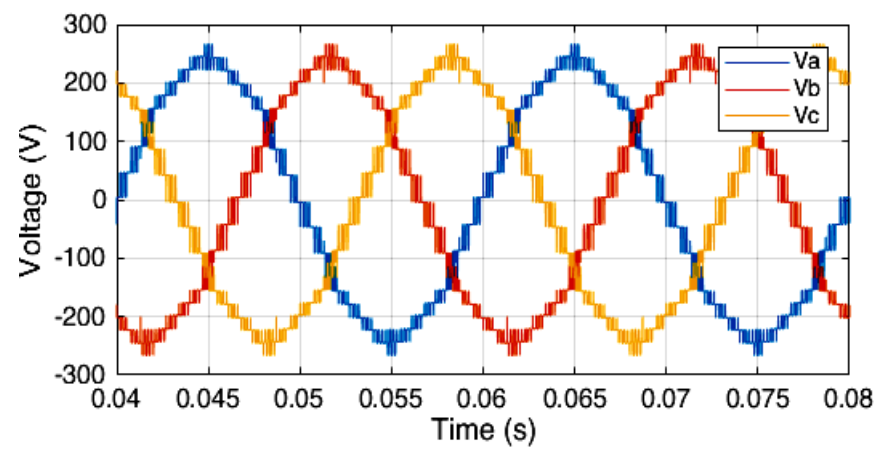

Figure 13. Output phase voltage Vabc

Table 3. Parameters of the permanent magnet synchronous machine

\begin{tabular}{cc}
\hline Parameters & Specification \\
\hline Rated Speed & $3000 \mathrm{RPM}$ \\
Rated Torque & $111 \mathrm{~N} . \mathrm{m}$ \\
Rated Voltage & $560 \mathrm{~V}$ \\
Number of Poles & 4 \\
Lq & $0,000635 \mathrm{H}$ \\
Ld & $0,000635 \mathrm{H}$ \\
rs & $0,05 \Omega$ \\
Flux $(\varphi)$ & $0,192 \mathrm{~Wb}$ \\
Inertia $(J)$ & $0,011 \mathrm{~kg} . \mathrm{m}^{2}$ \\
Friction & $0,001889 \mathrm{~N} . \mathrm{m} . \mathrm{s}$ \\
\hline
\end{tabular}

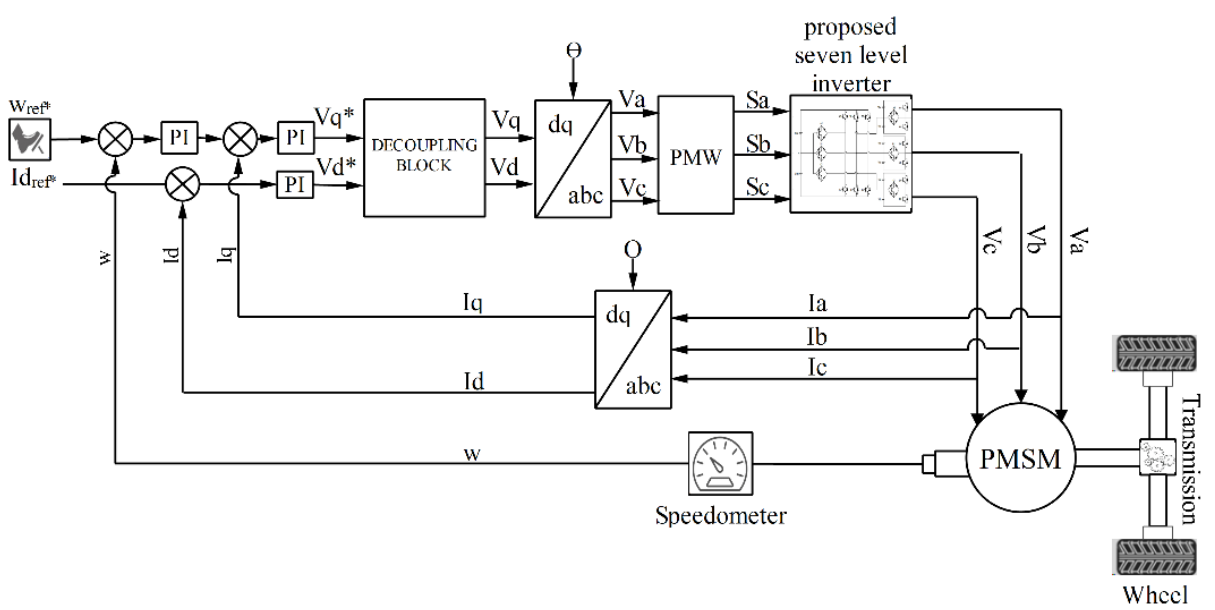

Figure 14. Electric traction system based on seven-level inverter of the proposed topology 


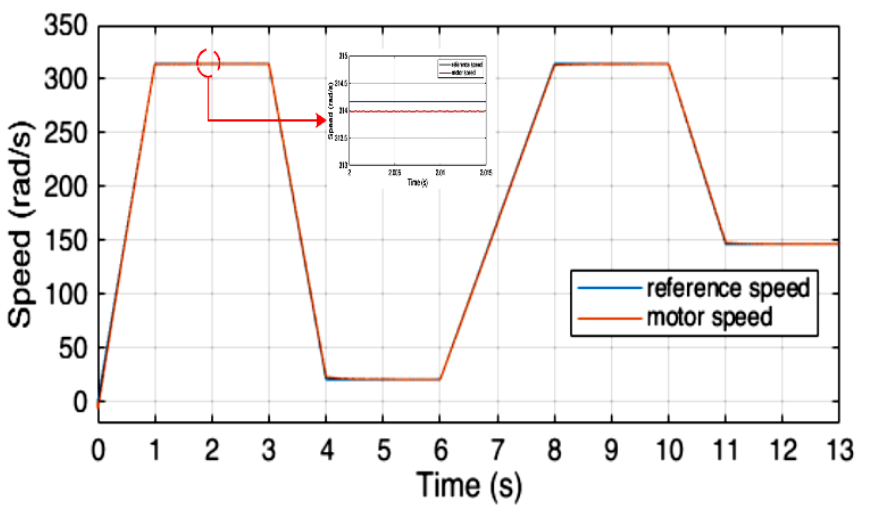

(a) PMSM speed

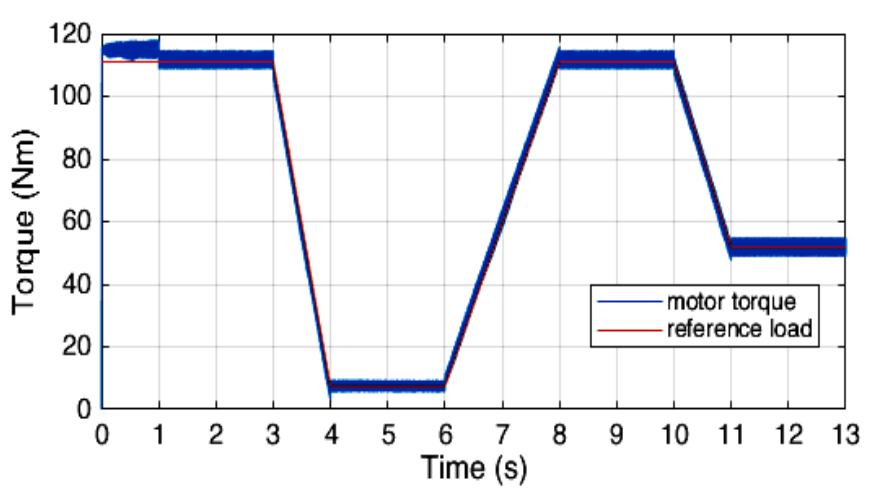

(b) PMSM torque

Figure 15. PMSM speed and torque curves

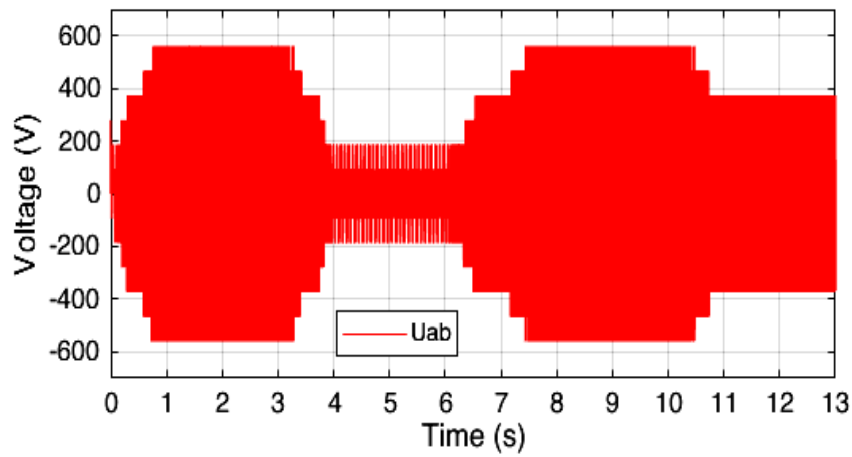

(a) Line voltage Uab

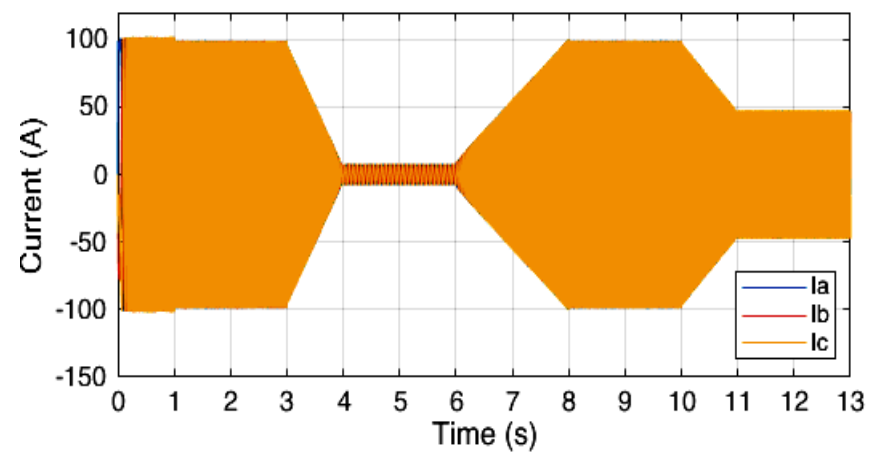

(b) Phase currents Iabc

Figure 16. Line voltage Uab and phase currents Iabc waveforms

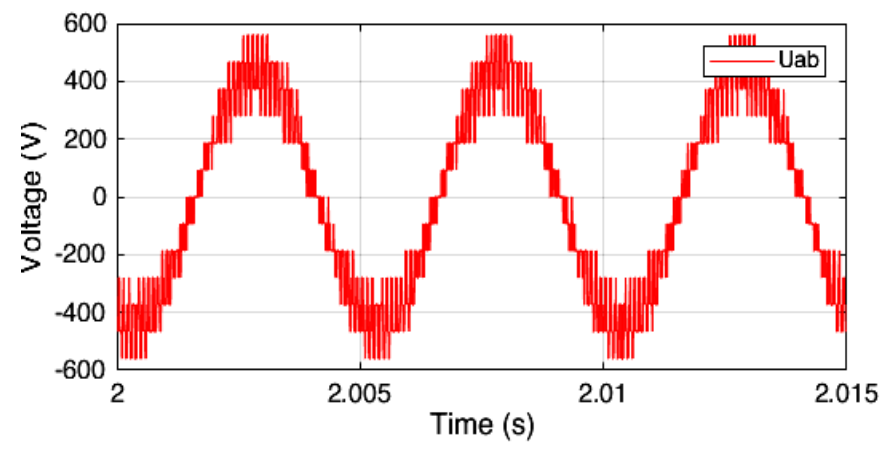

(a) Line voltage Uab

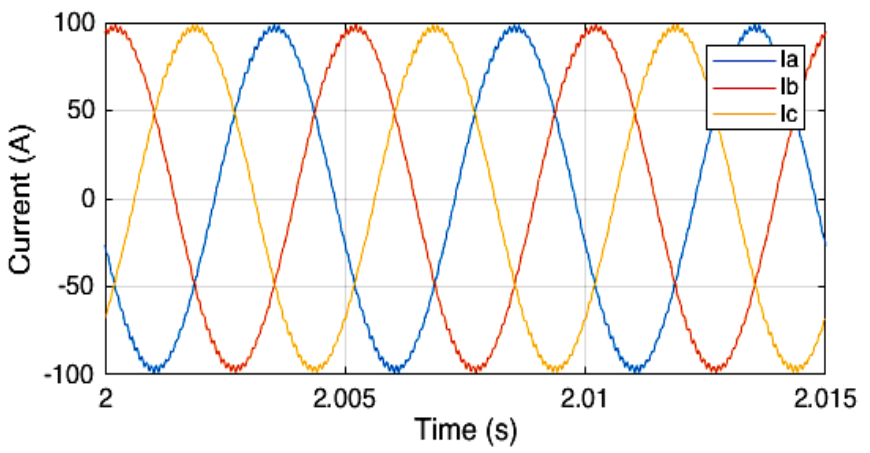

(b) Phase currents Iabc

Figure 17. Line voltage Uab and phase currents Iabc waveforms at $314 \mathrm{rad} / \mathrm{s}$ speed and of $111 \mathrm{Nm}$ torque

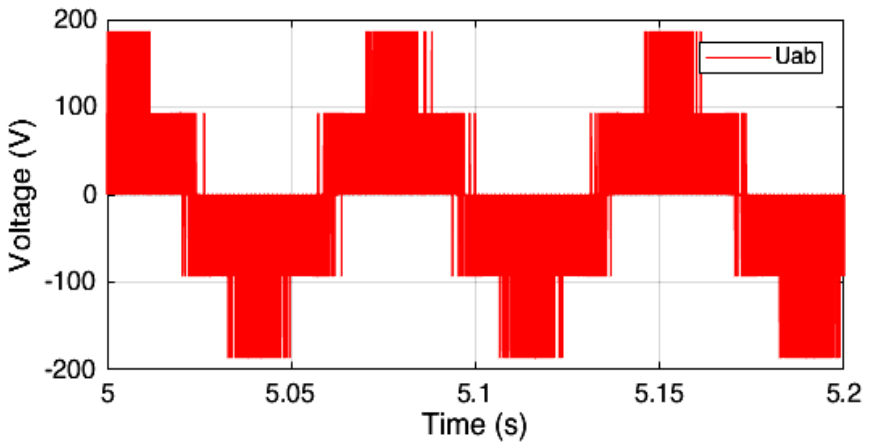

(a) Line voltage Uab

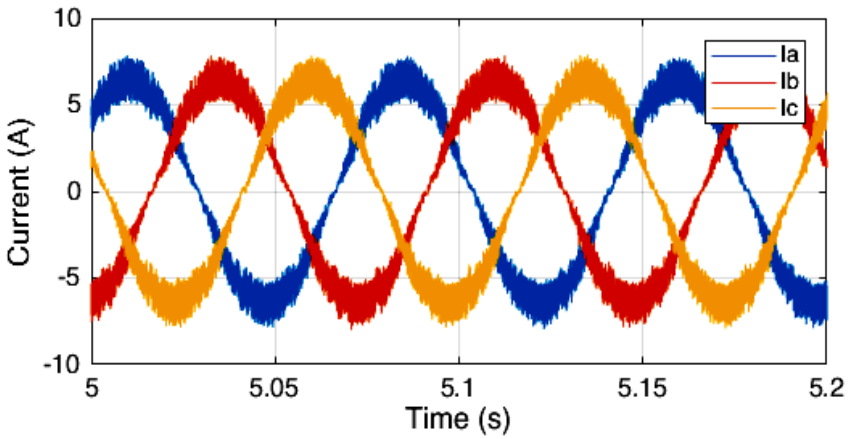

(b) Phase currents Iabc

Figure 18. Line voltage Uab and phase currents Iabc waveforms at of $21 \mathrm{rad} / \mathrm{s}$ speed and of $8 \mathrm{Nm}$ torque 


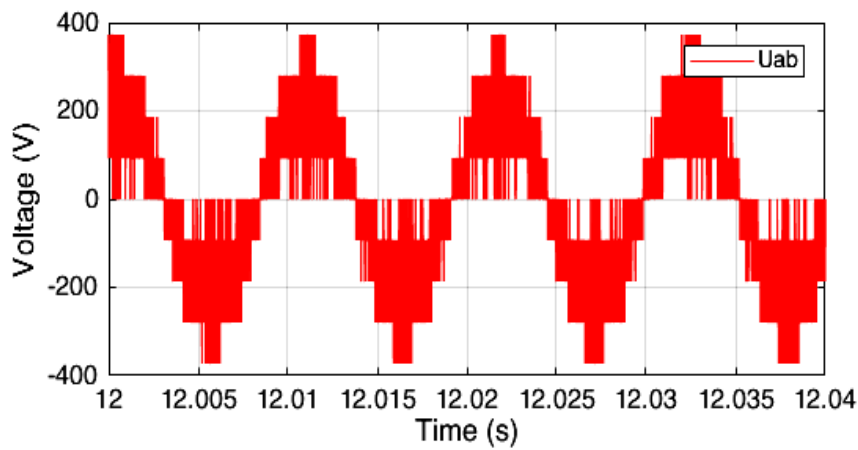

(a) Line voltage Uab

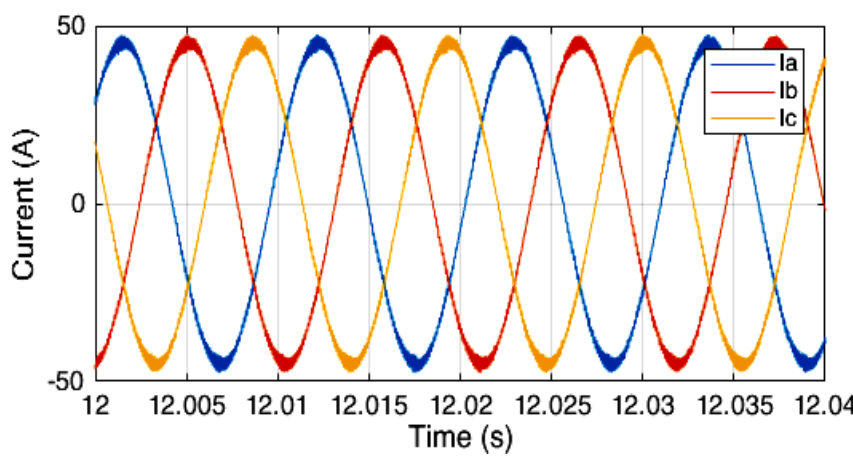

(b) Phase currents Iabc

Figure 19. Line voltage Uab and phase currents Iabc waveforms at $147 \mathrm{rad} / \mathrm{s}$ speed and of $52 \mathrm{Nm}$ torque
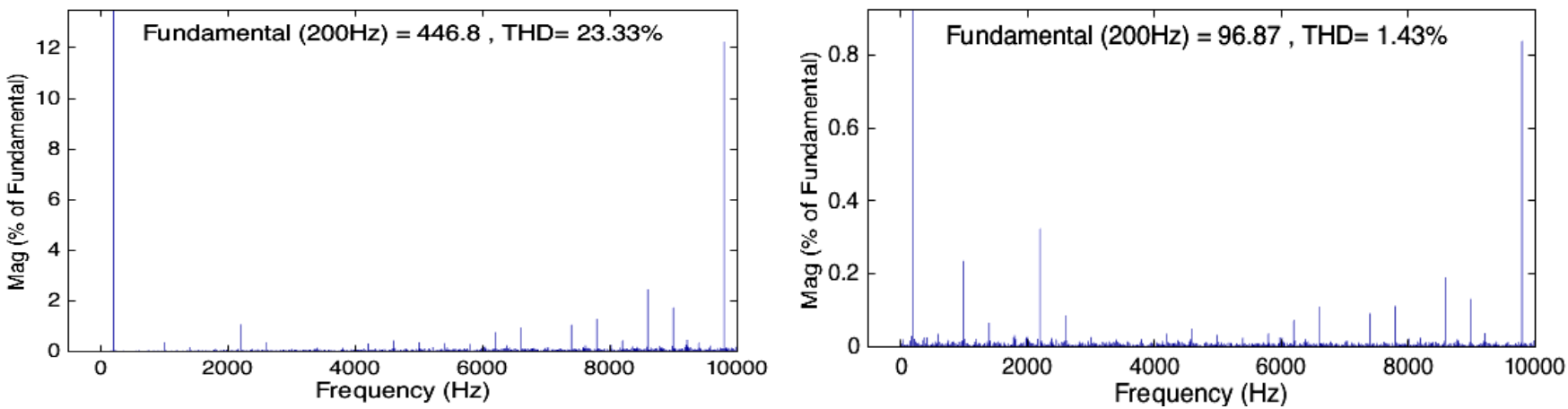

Figure 20. Voltage and current harmonic distortion analysis at the synchronism speed and maximum torque

It is well known, in FOC technique, that the target control parameter is the motor speed. In our case, a speed cycle representing a different situation. Such as high, medium and low speed (Figure 14(a)) respectively ( $314 \mathrm{rad} / \mathrm{s}, 147 \mathrm{rad} / \mathrm{s}$ and $21 \mathrm{rad} / \mathrm{s})$. Under load variation condition as depicted in Figure 14(b).

Figure 15(a) shows that the motor speed follows its reference throughout the cycle. This is because of the good waveforms of voltage provided by the seven-level inverter of the proposed topology as show in Figure 17(a), 18(a) and 19 (a). Moreover, the current (Figure 17(b), 18(b) and 19(b)) presents also sinusoidal waveforms which has a direct impact on the motor torque.

The good quality of the current waveform is resulting from that of the supplying voltage as it is illustrated in Figure 20.

\section{CONCLUSION}

This paper presents a novel multilevel inverter topology dedicated to Electric Traction drive based on proposed threelevel module unit. The proposed multilevel topology provides some advantages over those already proposed in literature. The main advantages are the reduced number of controlled switches with the possible extending the number of levels and phases, and also to design a modular or compact topology. The reduced number of switches provides a costs reduction and low complexity of control. Moreover, the proposed basic module unit topology can be inserted with any other compact multilevel inverter to increase its level number.

A three phase seven-level inverter of the proposed topology is used in electric traction drive system based on PMSM with field-oriented control technique. The obtained results, in terms of motor speed, show a good reference tracking because of the high quality of voltage and current waveforms. This will increase the battery lifetime and the reliability of the global electric traction system.

\section{REFERENCES}

[1] Tolbert, L.M., Peng, F.Z., Habetler, T.G. (1999). Multilevel converters for large electric drives. IEEE Transactions on Industry Applications, 35(1): 36-44. https://doi.org/10.1109/28.740843

[2] Tolbert, L.M., Peng, F.Z., Habetler, T.G. (1998). Multilevel inverter for electric vehicle applications. Power Electronics in Transportation (Cat. No.98TH8349), Dearborn, MI, USA, pp. 79-84. https://doi.org/10.1109/PET.1998.731062

[3] Welchko, B.A., Nagashima, J.M. (2003). The influence of topology selection on the design of $\mathrm{EV} / \mathrm{HEV}$ propulsion systems. IEEE Power Electronics Letters, 1(2): 36-40. https://doi.org/10.1109/LPEL.2003.821033

[4] Gautam, S.P., Kumar, L., Gupta, S. (2015). Hybrid topology of symmetrical multilevel inverter using less number of devices. IET Power Electronics, 8(11): 21252135. https://doi.org/10.1049/iet-pel.2015.0037

[5] Omer, P., Kumar, J., Surjan, B.S. (2020). A review on reduced switch count multilevel inverter topologies. IEEE Access, 8: 22281-22302. https://doi.org/10.1109/ACCESS.2020.2969551

[6] Rodriguez, J., Franquelo, L.G., Kouro, S., Leon, J.I., Portillo, R.C., Prats, M.A.M., Perez, M.A. (2009). Multilevel converters: An enabling technology for highpower applications. Proceedings of the IEEE, 97(11): 1786-1817.

https://doi.org/10.1109/JPROC.2009.2030235 
[7] Sun, B., Wu, F., Dragi cevi, T., Guerrero, J.M., Vasquez, J.C. (2014). A single-phase seven-level grid-connected inverter based on three reference SPWM strategy. 2014 IEEE International Energy Conference (ENERGYCON), Cavtat, pp. 222-227. https://doi.org/10.1109/ENERGYCON.2014.6850432

[8] Hinago, Y., Koizumi, H. (2012). A switched-capacitor inverter using series/parallel conversion with inductive load. IEEE Transactions on Industrial Electronics, 59(2): 878-887. https://doi.org/10.1109/TIE.2011.2158768

[9] Choupan, R., Golshannavaz, S., Nazarpour, D., Barmala, M. (2019). A new topology for multilevel inverters with fault-tolerant capability against open circuit faults. Electric Power Systems Research, 168: 105-116. https://doi.org/10.1016/j.epsr.2018.11.013

[10] Peng, W., Ni, Q., Qiu, X., Ye, Y. (2019). Seven-level Inverter with Self-Balanced Switched-Capacitor and Its Cascaded Extension. IEEE Transactions on Power Electronics, 34(12): 11889-11896. https://doi.org/10.1109/TPEL.2019.2904754

[11] Chen, J., Wang, C., Li, J. (2019). A single-phase step-up seven-level inverter with a simple implementation method for level-shifted modulation schemes. IEEE Access, $\quad 7$ : 146552-146565. https://doi.org/10.1109/ACCESS.2019.2946238

[12] Hsieh, C.H., Liang, T.J., Chen, S.M., Tsai, S.W. (2016). Design and implementation of a novel multilevel dc-ac inverter. IEEE Transactions on Industry Applications, 52(3): 2436-2443. https://doi.org/10.1109/TIA.2016.2527622

[13] Yadav, A.K., Gopakumar, K., Loganathan, U., Bhattacharya, S., Jarzyna, W. (2019). A hybrid sevenlevel inverter using low voltage devices and operation with single DC-link. IEEE Transactions on Power Electronics, 34(10): 9844-9853. https://doi.org/10.1109/TPEL.2018.2890371

[14] Sanjeevan, A.R., Kaarthik, R.S., Gopakumar, K., Rajeevan, P.P., Leon, J.I., Franquelo, L.G. (2016). Reduced common-mode voltage operation of a new seven-level hybrid multilevel inverter topology with a single DC voltage source. IET Power Electronics, 9(3): 519-528. https://doi.org/10.1049/iet-pel.2015.0130

[15] Siwakoti, Y., Mahajan, A., Rogers, D., Blaabjerg, F. (2019). A novel seven-level active neutral point clamped converter with reduced active switching devices and DClink voltage. IEEE Transactions on Power Electronics, 34(11): 10492-10508. https://doi.org/10.1109/TPEL.2019.2897061

[16] Lee, S.S. (2018). A single-phase single-source 7-level inverter with triple voltage boosting gain. IEEE Access, 6: 30005-30011.
https://doi.org/10.1109/ACCESS.2018.2842182

[17] Pulikanti, S.R., Konstantinou, G., Agelidis, V.G. (2013). Hybrid seven-level cascaded active neutral-pointclamped-based multilevel converter under SHE-PWM. IEEE Transactions on Industrial Electronics, 60(11): 4794-4804. https://doi.org/10.1109/TIE.2012.2218551

[18] Lee, S.S., Lee, K.B. (2019). Dual-T-type seven-level boost active-neutral-point-clamped inverter. IEEE Transactions on Power Electronics, 34(7): 6031-6035. https://doi.org/10.1109/TPEL.2019.2891248

[19] Zeng, J., Lin, W., Liu, J. (2019). Switched-capacitorbased active-neutral-point-clamped seven-level inverter with natural balance and boost ability. IEEE Access, 7: 126889-126896. https://doi.org/10.1109/ACCESS.2019.2927351

[20] McGrath, B.P., Holmes, D.G. (2002). Multicarrier PWM strategies for multilevel inverters. IEEE Transactions on Industrial Electronics, $\quad$ 49(4): 858-867. https://doi.org/10.1109/TIE.2002.801073

[21] Wu, X., Zhu, Z.Q., Wu, Z., Liu, T., Li, Y. (2020). Analysis and suppression of rotor eccentricity effects on fundamental model based sensorless control of permanent magnet synchronous machine. IEEE Transactions on Industry Applications. https://doi.org/10.1109/TIA.2020.2997297

[22] Wang, G., Valla, M., Solsona, J. (2020). Position sensorless permanent magnet synchronous machine drives - a review. IEEE Transactions on Industrial Electronics, 67(7): 5830-5842. https://doi.org/10.1109/TIE.2019.2955409

\section{NOMENCLATURE}

$\begin{array}{ll}\text { Cr } & \text { Carrier } \\ \text { DC } & \text { Direct Current } \\ \text { FC } & \text { floating capacitor } \\ \text { FOC } & \text { Field Oriented Control } \\ \text { IGBT } & \begin{array}{l}\text { Insulated Gate Transistors with } \\ \text { Bipolar junction } \\ \text { J }\end{array} \\ \text { NPC } & \text { Noment of inertia } \\ \text { N } & \text { Number of levels } \\ \text { M } & \text { Number of modules to be added } \\ \text { PWM } & \text { Pulse Width Modulation } \\ \text { PODPWM } & \text { Phase Opposition Disposition Pulse } \\ & \text { Width Modulation } \\ \text { THD } & \text { Total Harmonic Distortion } \\ \text { Vdc } & \text { Continuous voltage }\end{array}$

